\title{
Use of conspicuity aids by cyclists and risk of crashes involving other road users: population based case-control study.
}

Philip D Miller ${ }^{a, b *}$, Denise Kendrick ${ }^{a}$, Carol Coupland ${ }^{a}$, Frank Coffey ${ }^{b}$

a Division of Primary Care, School of Medicine, University of Nottingham, The Tower, University Park, Nottingham, NG7 2RD, United Kingdom

b Emergency Department, Nottingham University Hospitals NHS Trust, Derby Road, Nottingham, NG7 2UH, United Kingdom

* Corresponding Author

Email addresses:

Philip Miller:

p.miller@nottingham.ac.uk

Denise Kendrick:

denise.kendrick@nottingham.ac.uk

Carol Coupland:

carol.coupland@nottingham.ac.uk

Frank Coffey:

frank.coffey@nuh.nhs.uk 


\begin{abstract}
Background:

Cycling can improve health and well-being by reducing inactivity. Concern about collision crashes may be a barrier to participation since collision crashes can lead to significant mortality and morbidity. The conspicuity of cyclists may be a contributory factor in some collision crashes. This study investigated whether increased conspicuity aid use (such as reflective or fluorescent clothing) is associated with a reduced risk of collision crashes for cyclists in a UK city.
\end{abstract}

\title{
Methods:
}

A matched case-control study was undertaken. Cases were adult cyclists involved in a collision crash causing injury. Controls were adult cyclists matched to cases by time of day, day of week and geographical area of travel. Exposures, potential confounders and route were reported by participants. Odds ratios (OR) and $95 \%$ confidence intervals were calculated using conditional logistic regression.

\section{Results:}

76 cases and 272 controls were included. $69.7 \%$ of cases and $65.4 \%$ of controls reported using a conspicuity aid on the crash (cases) or index (controls) journey. The unadjusted OR for a collision crash when using any conspicuity aid vs none was $1.2(95 \% \mathrm{Cl} 0.7$ to 2.2 ) and 2.4 (95\% Cl 1.1 to 5.6) after adjustment for age, gender, index of multiple deprivation score, route risk score and previous bicycle crash.

\section{Conclusion:}

This study found no evidence that cyclists using conspicuity aids were at reduced risk of a collision crash compared to non-users after adjustment for confounding, but there was some evidence of an increase in risk. Bias and residual confounding from differing route selection and cycling behaviours in users of conspicuity aids are possible explanations for these findings. Conspicuity aids may not be effective in reducing collision crash risk for cyclists in highly-motorised environments when used in the absence of other bicycle crash prevention measures such as increased segregation or lower motor vehicle speeds. 


\section{Keywords}

road traffic injury; vulnerable road user; conspicuity; bicycle; injury prevention. 


\section{Introduction}

Regular cycling has been shown to improve health and well-being and has a role in tackling obesity and inactivity (1-4). The total distance travelled by bicycle in Britain has declined from 24 billion kilometres in 1948 to around 5.2 billion kilometres in 2014 which equates to around $1 \%$ of all travel (5). In 2015 the average person travelled 5,159 miles by car, 184 miles on foot but only 53 miles by bicycle (6).

Cycle collisions, particularly those involving motorised vehicles, can lead to considerable mortality and morbidity $(7,8)$. In addition to these direct consequences, participation in cycling may be reduced in highly motorised environments in part because of the widely held view that cycling is dangerous (9). There is emerging evidence that "near-miss" incidents involving no injury are common and act as a considerable disincentive to cycling $(10,11)$. Low rates of cycling may increase risk for individual cyclists as increases in numbers of people cycling are associated with lower rates of bicycle crashes for individuals (12-14).

There is evidence that the conspicuity of cyclists may be a factor in some collision crashes (15). Late detection by drivers of other road users has been highlighted as the most 'basic driver error' leading to collisions (16). Many drivers report not being aware of cyclists prior to collisions (17). Detailed analyses of crashes suggest that cyclists may be difficult for drivers to detect owing to their road position, low relative speed and small size (18). Given these findings it is reasonable to ask whether increasing the conspicuity of cyclists could reduce the incidence of collision crashes.

Moderate to low-cost retro-reflective and fluorescent clothing and accessories are widely available for use by cyclists. There are a considerable variety of configurations of such materials in use by cyclists, many of which include both modes of action incorporated in parts of jackets or trousers or worn over other clothing ("snap-wraps", gilets or "Sam Browne" belts etc). A systematic review examining the literature concerning the effectiveness of conspicuity aids found test-circuit and simulated studies only and concluded that they can increase the distances at which drivers can detect and then recognise cyclists and pedestrians (19). The review found no studies which reported the effectiveness of conspicuity aids in reducing collision crashes for cyclists. The use of such aids by cyclists is 
poorly understood. One study found relatively low rates of use by urban cyclists observed in a Canadian city during daylight hours (20). Other published findings suggest that cyclists estimate the potential for such clothing to increase conspicuity to be greater than do car drivers (21). It has also been suggested that some cyclists may assume that the use of lights alone may be sufficient to make them conspicuous at night and therefore that there is little benefit in using additional conspicuity apparel (22).

There is some evidence that the use of conspicuity aids is associated with a reduction in odds in both motorcyclists and cyclists although this is inconsistent. A case-control study of crash-involved motorcyclists in New Zealand reported a 37\% reduction in the odds of a crash for riders who were using conspicuity aids at the time of the crash compared to those who did not (OR $0.63 ; 95 \% \mathrm{Cl} ; 0.42$ to 0.94$)(23)$. An analysis of data collected via an online survey from cyclists in a public cycling event in New Zealand also suggested that there may be a protective effect of conspicuity aid use with a $28 \%$ reduction in the odds of a crash for cyclists who reported always wearing fluorescent colours compared to those who reported never wearing them (24). Both studies included crashes where the rider lost control with no other road user being involved despite it being unlikely that conspicuity is a causal factor in incidents of this type. More recently a re-analysis of longer-term follow-up data from the bicycle study in New Zealand restricted to bicycle/motor-vehicle collision crashes showed an increased risk for cyclists using greater amounts of conspicuity aids in some geographical regions but not in others (25). An analysis of Canadian cyclists injured in collisions involving motor vehicles compared to cyclist-only crashes found light-coloured upper body clothing to be protective in daylight (26). Fluorescent and reflective clothing in various combinations was not found to reduce crash risk in daylight or darkness, whilst red/yellow/orange upper body clothing and having tail lights on were both associated with an increased odds of collision in darkness. There was a reduction in the risk of hospitalisation among cyclists using one or more conspicuity aids (adjusted OR $0.21 ; 95 \% \mathrm{Cl} 0.04$ to 1.00 ) and this was significant for those using two or more aids (adjusted OR 0.10; $95 \% \mathrm{Cl} 0.02$ to 0.41 ).

The study reported in this paper was designed to investigate the relationship between the use of conspicuity aids and the risk of injury requiring emergency department assessment or treatment after a crash for cyclists involving other road users in an urban setting in the UK. 


\section{Material and Methods}

\subsection{Study design}

A matched case-control study was undertaken as described in the published protocol (27).

\subsection{Selection of cases}

Cases were adult cyclists, aged 16 and over, involved in a crash resulting from a collision or attempted evasion of a collision with another road user and who attended the emergency department (ED) at the Nottingham University Hospitals Trust for assessment and treatment of their injuries. Cyclists were eligible for inclusion if they were commuting to work (defined as making a journey to or from their place of work or study or on a work or study related trip) or for utility purposes (defined as travelling for a purpose such as shopping where they would park or dismount in a public place at some point during their journey). Cyclists were excluded if they were travelling for leisure, training or competitive purposes owing to the likely differences between such cyclists and commuter or utility cyclists and also the practical difficulty of recruiting similar controls engaged in these activities. In addition cases were excluded if they had been fatally injured, if their crash occurred between $11 \mathrm{pm}$ and 5 am or if their crash occurred outside the study catchment area (the catchment area of Nottingham University Hospitals NHS Trust ED).

The majority of cases were identified from ED records and contacted by post, in addition a small number of case cyclists were approached and recruited during their initial attendance at ED.

\subsection{Selection of controls}

Controls were commuter or utility cyclists recruited at company or organisational premises or public places prior to or following a cycle journey within the same geographical area as cases. Controls were recruited between 6 am and $10 \mathrm{pm}$ over 7 days per week on an 
incidence density basis with a target ratio of four controls per case. They were individually matched to cases by journey time (to within plus or minus 1 hour of the case's crash time) and day of the week within six weeks of their case's crash, to reduce confounding from short-term and seasonal variations in traffic patterns, environmental conditions and changes in available cycling populations at risk at different times of day. Recruitment and data collection for cases and controls was completed between June 2008 and July 2010. Controls were approached by a researcher and informed about the study. If they agreed to take part they were given a questionnaire to complete.

\subsection{Data collection}

Data on the use of conspicuity aids was collected using self-completed questionnaires. Participants were asked to record their use of reflective and fluorescent items of clothing and equipment on the crash journey (cases) or the index journey on the day of recruitment (controls). Data were also collected on demographic characteristics (age, sex, ethnic group), years of cycling experience, previous cycling injuries, bicycle use, cycle helmet use, psychological traits associated with risk-taking behaviour (Normlessness (28) and sensation seeking $(28,29))$ and the prevailing light and weather conditions during their journey. Index of multiple deprivation scores (30) were derived using postcodes for the homes of participants. Participants were asked to illustrate the route of their crash journey (cases) or index journey (controls) on maps of the study area supplied with the questionnaire.

A measure of cycling injury risk was derived for each of the routes provided by the participating cyclists. To calculate this measure, observations of cyclist numbers were made by a researcher over two hour intervals during peak and off-peak periods at randomly selected sites along each participant's route. The numbers of police recorded bicycle injury crashes along the route in the previous three years was also calculated using information extracted from publicly available data for the three years immediately preceding the study period

(http://webarchive.nationalarchives.gov.uk/20121017175053/http://innovate.direct.gov.uk L2009/03/10/pedalling-some-raw-data/ last accessed 05/02/2016) The data on cyclist numbers, previous recorded bicycle crashes and route length were combined to give an estimate of the number of cycle crashes per 100 million cyclists per kilometre along each 
participant's route to adjust for potential confounding from this source (see Appendix 1 in supplement).

\subsection{Exposures}

The primary exposure of interest was use of any conspicuity aid (reflective or fluorescent on upper body or lower body clothing or on cycle helmet) on the index journey.

Other exposure variables were any fluorescent or retro-reflective or light coloured materials worn as part of upper or lower body clothing or cycle helmet, cycle-mounted reflectors, front or rear lights and any other safety equipment intended to increase conspicuity.

\subsection{Validation study}

To validate the self-reported responses on conspicuity aid use, independent observations of the use of fluorescent and retro-reflective clothing and cycle helmet use of cases and controls were undertaken by a researcher during face to face recruitment at matched sites (controls) and within the local Emergency Department when possible (cases).

\subsection{Sample Size}

Two observers (PM and DK) recorded conspicuity aid use amongst cyclists within the study area during peak hours as a pilot study to inform the sample size calculation. The proportion of cyclists observed to be using any fluorescent or reflective clothing or item was $44 \%$ during peak hours ( $n=64 ; 95 \% \mathrm{Cl} 31 \%$ to $57 \%$ ). It was assumed that the majority of cyclists at this time were commuters and that this represented a realistic estimate of exposure for the target population. A power calculation showed that with a $44 \%$ prevalence of use 218 cases and 872 matched controls were required with a matched case-control correlation of 0.2 and a ratio of $1: 4$ cases to controls, to give the study $80 \%$ power ( 2 -sided alpha $=0.05$ ) to detect an OR of 0.63 for collision crash when using conspicuity aids.

\subsection{Statistical Analysis}

All analyses were conducted using Stata version 10 (Stata Corp, Texas, USA). The characteristics of cases and controls were described using proportions, means and standard deviations or medians and inter-quartile ranges as appropriate. 
Conditional logistic regression was used to estimate ORs with $95 \%$ confidence intervals to quantify the relationship between the exposures of interest and the odds of collision or evasion crash. To account for potential confounding variables first age and gender were included in the model as a priori variables, then a backwards elimination process was used starting from an initial model containing all potential confounders with a Wald significance value less than 0.25 in a univariate analysis (31). Third, confounders were removed from the model if their removal altered the OR for the primary exposure variable (conspicuity aid use) by less than $10 \%$ (32). The linearity of continuous covariates with the outcome was tested and variables were categorised where appropriate. Interactions between conspicuity aid use and covariates in the final model were assessed using likelihood ratio tests and deemed significant if $p<0.05$.

Validation of the self-reported primary exposure variable was undertaken by comparison to independent observations. Agreement was estimated using kappa coefficients with $95 \%$ confidence intervals. The sensitivity, specificity and positive and negative predictive values of self-reported exposures were calculated using the independent observations as the reference values.

\subsection{Ethical approval}

The study was reviewed and approved by Nottingham Research Ethics Committee 1 (ref. 08/H0407/13) and authorization to conduct the research at the study site was given by the Research and Development Department of the Nottingham University Hospitals NHS Trust (ref. 07AE003).

\section{Results}

After application of the inclusion and exclusion criteria 76 cases and 272 controls were eligible for inclusion in the primary analysis. The recruitment process is shown in Figure 1. It was not possible to calculate the true proportion of eligible cases recruited as information 
on collision crash involvement as opposed to non-collision crashes could not be ascertained for non-responders.

The characteristics of study participants are described in Table 1, along with unadjusted ORs. Cases were significantly younger than controls (mean 36 years vs 41 years), more likely to be male (77.6\% vs 63.2\%), more likely to live in a deprived area (index of multiple deprivation median 20 vs 13 ) and were less likely to hold a driving licence (69.7\% vs $84.2 \%$ ).

Information on bicycle use, cycling experience and characteristics of the index journey for cases and controls is shown in Table 2 with unadjusted ORs. The number of years of regular cycling as an adult differed significantly between cases and controls with the proportion of cases reporting less than a year of regular cycling experience being nearly twice that of controls (21.1\% vs. $11.5 \%)$ and fewer cases than controls reporting cycling regularly for more than 10 years ( $44.7 \%$ vs. $60.0 \%$ ). Cases and controls did not differ significantly in the distance they had cycled or the numbers of trips they made in the seven days prior to their reported index journey. Increasing route risk scores were associated with significantly higher odds of a crash such that for every 100 additional recorded bicycle crashes per 100 million cyclists per kilometre there was a $19 \%$ increase in the odds of a crash $(95 \% \mathrm{Cl} 6 \%$ to $33 \%)$. Riding a racing or mountain bike rather than a commuter or folding bike was associated with a significantly increased crash risk. The proportions using cycle helmets were similar in both groups. Cycling during overcast conditions or at dawn or dusk was associated with a significantly lower crash risk compared with daylight.

Details of conspicuity aid use are presented in Table 3. Cases and controls were similar overall in their use of conspicuity aids with $65.4 \%$ of controls and $69.7 \%$ of cases reporting use of any fluorescent or reflective clothing or item (unadjusted OR 1.20, 95\% Cl 0.66 to 2.17). Cases were significantly more likely than controls to report wearing fluorescent helmets and having reflective materials on the lower body although the numbers using either aid were small. The proportions of cases and controls using fixed conspicuity aids (e.g. reflectors, lights etc) were very similar overall. The use of lit lights (flashing and constant patterns combined) was associated with increased odds of a crash (unadjusted OR 1.59, 95\% 
$\mathrm{Cl} 0.67$ to 3.78 ) and was associated with conspicuity aid use (unmatched $\mathrm{OR} 4.46,95 \% \mathrm{Cl}$ 2.40 to 8.28 ) but had minimal influence on the odds ratio in the multivariate model.

Table 4 shows unadjusted associations between participant and bicycle use characteristics, and the use of conspicuity aids (use of any fluorescent or reflective clothing or item). The use of conspicuity aids was significantly higher among participants who had been involved in a previous bicycle crash, who used a cycle helmet, who were travelling in darkness and whose journey was greater than the median route distance (5.2 kilometres). There was no significant association between use of conspicuity aids and the route risk estimate.

The great majority of case journeys were undertaken during daylight hours and these were matched to control recruitment on an incidence-density basis. Daytime crashes are common and we included them given the hypothesis given that fluorescent materials are only effective in the presence of ultraviolet light and are therefore thought to be most effective when daylight is present but limited e.g. dawn or dusk.

In the multivariable analysis after adjustment for confounding from age, gender and other confounders which altered the estimated OR for use of conspicuity aids by greater than $10 \%$ (namely deprivation, route risk and history of a previous cycle crash) the use of conspicuity aids was associated with a significant increase in the odds of a crash (OR 2.43; 95\% Cl 1.06 to 5.59) (Table 5). Odds ratios for conspicuity aid use adjusted by individual confounding variables are shown in Table 6. The greatest changes in ORs were for adjustment by cycling experience, helmet use and route risk which all resulted in increases in the OR for conspicuity aid use.

\section{Validation of exposure data}

Independent observations on use of any fluorescent or reflective clothing or item were made for 369 potential controls and 15 potential cases during recruitment, and 224 of these controls and 4 cases returned questionnaires and were eligible for the main study. Among these 228 participants the kappa coefficient for agreement between the self-reported and independently observed exposures for eligible participants was 0.42 ( $95 \% \mathrm{Cl} 0.32$ to 0.51 ). Appendix B shows numbers in each category with sensitivity and specificity values. 


\section{Discussion}

\subsection{Principle findings and their interpretation}

This study found no evidence that the use of conspicuity aids was associated with a reduced odds of a collision crash for cyclists. Instead it was found that there was an increased odds of a collision crash associated with use of conspicuity aids after adjustment for confounding from measurable sources. This result is inconsistent with the body of evidence suggesting that conspicuity aids are effective in increasing detection and recognition distances in testcircuit and otherwise simulated road conditions $(15,19)$. These results do however support some other findings in the recent literature showing little or no protective benefit and even some potential for increased collision crash risk from the use of conspicuity aids in motorised traffic environments $(25,26)$.

Taken together this emerging body of evidence suggests that a "risk over-compensation" effect may be at work. Cyclists who choose to wear conspicuity aids may increase their exposure to motorised traffic or conversely, conspicuity aids may be worn if a journey is thought to involve greater exposure to traffic danger. Also cyclists who wear conspicuity aids may alter their behaviour in traffic. Such behavioural adaptations could give rise to an increased risk of collisions if cyclists using conspicuity aids believe themselves to be more conspicuous to motorists than they actually are. Conspicuity aids along with lights and reflectors are among the safety equipment items that cyclists commonly adopt to reduce their risk of collision crashes. The degree to which such equipment does reduce collision risk in real traffic environments is potentially limited and in turn cyclists' beliefs about efficacy may alter choice of route, voluntary exposure to motorised traffic and cycling behaviour in ways which place them at greater risk than would otherwise choose.

This study was able to adjust for a number of sources of potential confounding including that posed by route selection and risk from traffic. There were significant differences in the level of crash risk represented by the routes chosen by cases and controls but no significant association between the use of conspicuity aids and travelling on more dangerous routes 
based on the measure of route risk used in this study. This suggests that conspicuity aid users do not compensate for increased perceived conspicuity by selecting routes with greater exposure to traffic risk. However the second form of compensatory behaviour may have occurred if there were changes in cyclist's behaviour in traffic as a result of their use of conspicuity aids. For example, users may have adopted more exposed road positions or manoeuvres involving crossing the path of motorised vehicles more frequently in the belief that they were relatively conspicuous. If such compensatory behaviour was common amongst users this could explain why the study did not show the protective effect from conspicuity aid use predicted by experiments under "laboratory" conditions where subjects were not at actual risk of injury. Such differences in behaviour are difficult to measure and may not be well represented in our study by proxy measures such as age or cycling experience.

Conspicuity aid use may also lead to compensatory changes in road behaviour by other road users who encounter cyclists. A study conducted on the UK road system at four sites, two rural and two suburban, measured the passing distances of motor vehicles overtaking a cyclist using different conspicuity aids (33). Across the four sites the use of a fluorescent vest did not increase the passing space afforded the cyclist by motor vehicle drivers, but at one of the suburban sites there was a significant increase in passing space when the vest was used with a mean increase of $61 \mathrm{~mm}$, and a corresponding reduction in the proportion of passes within one metre but this did not occur on rural roads. There were significant increases in passing distances with use of a side bar with either a flag or a reflective disc projecting to the off side across the sites. More recent work has suggested that safety equipment use such as a cycle helmet is associated with a reduction in the passing distance of vehicles although conspicuity aids such as fluorescent vests were not tested (34). A recent interview study analysing cyclists' perceptions of safety clothing use suggests that use of conspicuity-enhancing clothing is associated with the level of subjective risk encountered especially from motorised traffic and that many participants were unsure of the degree of actual safety benefit conferred (35).

\subsection{Strengths and limitations}


The study described here represents the first published attempt to examine the effect of conspicuity aid use by cyclists on the odds of a collision crash adjusted for traffic environments as measured by previous bicycle crash incidence along the selected route. The relationship found between the odds of a crash and an objective measure of the route risk is novel. Our measure of route risk may however fail to capture all of the aspects of risk such as surface condition, infrastructure and traffic speeds and densities but represents a different approach to controlling for confounding in previous studies. Further research is needed to understand better the geographical distribution of traffic risk for cyclists, which features of the environment carry the most risk, how this impacts on the effects of safety practices and how such dangers can best be reduced.

There are a number of limitations to the study which mean that the results should be treated with caution. The participation rate was low, participants may have been aware of the hypothesis being explored and there is potential for recall bias. The number of participants recruited was lower than that required by the power calculation and the study lacks power to detect anything but a large protective effect and also to detect interactions with weather or lighting conditions. A larger multi-centre study is needed, with a higher participation rate and capture of exposure data from cases at the time of their crash to reduce recall bias.

It was only possible to makes independent observations of exposure data on a small number of cases as the majority could not be approached in person after their crash or they had disposed of the clothing they were wearing during the crash prior to being approached in person by the researcher. This means it was only possible to verify the reporting of selfreported exposures for a small proportion of cases compared to controls. The validity of this data could have been affected by recall or social desirability biases, where those involved in collisions may have reported what they perceived to be the socially acceptable responses (i.e. wearing conspicuity aids) to a greater extent than controls.

Overall the validation data, despite the small sample size, suggested that some respondents may have over-estimated their use of conspicuity aids, with only moderate agreement with the researcher classification. Misclassification bias if non-differential can lead to ORs tending 
towards unity; this is not necessarily the case if misclassification differs between cases and controls. Both cases and controls reported greater levels of use of conspicuity aids than that collected during field observations (44\%), but unlike the study participants these observations may have included leisure cyclists despite being recorded during the rush hour.

The relative performance of conspicuity aids was not measured directly to assess whether they conformed to existing safety standards. Some aids used by participants may have met safety standards whilst others were relatively ineffective, in poor condition or used inappropriately, but there is no reason to think this was likely to differ between cases and controls. The possibility remains that aids conforming to existing safety standards for protective equipment, in good condition and used appropriately may indeed be protective. This cannot be confirmed unless the relative conspicuity enhancing performance of participants' garments can be measured directly or otherwise standardised in future studies.

\section{Conclusion}

The results of this study suggest that interventions reliant on increasing cyclist conspicuity may not improve cyclists' safety in urban traffic environments in the UK. This is consistent with an emerging body of evidence from similar traffic environments in other developed countries showing little protective effect but further studies are required to confirm and explain these findings. Future research should aim to minimise the risk of biases and be designed to measure the effects of any compensatory behaviours by cyclists such as relatively greater tolerance of risks, resulting from their choice to use conspicuity aids. The variable distribution of traffic risk across the study area and its association with collision crash involvement suggest that reducing traffic danger by limiting motor vehicle speeds or increasing segregation of cyclists may be more fruitful approaches to reducing the current burden of injury for commuter and utility cyclists. 


\section{Conflicts of Interests}

None

\section{Authors' Contributions (INITIALS REMOVED FOR REVIEW PURPOSES)}

PM was responsible for recruitment, data collection and analyses and has written the manuscript. CC and DK proposed the original study design, co-authored the protocol and supervised the conduct and analysis of the study. FC is the local collaborator for the study and has commented on the manuscript and original design. All authors read and approved the final manuscript.

\section{Acknowledgments}

The authors wish to thank the many individual cyclists who participated in the study.

\section{Funding}

The study was sponsored by the University of Nottingham and funding was provided by the School of Community Health Sciences, University of Nottingham. 


\section{References}

1. Oja P, Vuori I, Paronen O. Daily walking and cycling to work: their utility as healthenhancing physical activity. Patient Education and Counseling. 1998;33(Supplement 1):S87-S94.

2. Andersen LB, Schnohr P, Schroll M, Hein HO. All-Cause Mortality Associated With Physical Activity During Leisure Time, Work, Sports, and Cycling to Work. Arch Intern Med. 2000;160(11):1621-8.

3. Bucksch J. Physical activity of moderate intensity in leisure time and the risk of all cause mortality. Br J Sports Med. 2005;39(9):632-8.

4. de Hartog JJ, Boogaard H, Nijland H, Hoek G. Do The Health Benefits Of Cycling Outweigh The Risks? Environ Health Perspect. 2010.

5. Department for Transport. Road traffic statistics: 2014. London; 2015.

6. Department for Transport. National Travel Survey: England 2015. London; 2016

7. European Road Safety Observatory. Traffic Safety Basic Facts 2007: Bicycles. SafetyNet; 2008.

8. Rivara F, Sattin RW. Preventing bicycle-related injuries: next steps. Inj Prev. 2011;17(3):215-.

9. Department for Transport. Attitudes to Walking and Cycling. HMSO; 2003.

10. Aldred $\mathrm{R}$, Crosweller $\mathrm{S}$. Investigating the rates and impacts of near misses and related incidents among UK cyclists. Journal of Transport \& Health. 2015;2(3):379-93.

11. Sanders RL. Perceived traffic risk for cyclists: The impact of near miss and collision experiences. Accident Analysis \& Prevention. 2015;75:26-34.

12. Jacobson PL. Safety in numbers: more walkers and bicyclists, safer walking and bicycling. Injury Prevention. 2003;9:205-9.

13. Schepers P. Does more cycling also reduce the risk of single-bicycle crashes? Injury Prevention. 2012;18(4):240-5.

14. Tin Tin S, Woodward A, Thornley S, Ameratunga S. Regional variations in pedal cyclist injuries in New Zealand: safety in numbers or risk in scarcity? Aust N Z J Public Health. 2011;35(4):357-63.

15. Knowles J. Collisions Involving Cyclists on Britain's Roads: Establishing the Causes. London 2010.

16. Rumar K. The basic driver error: late detection. Ergonomics. 1990;33(10-11):1281-90.

17. Rowe BH, Rowe AM, Bota GW. Bicyclist and environmental factors associated with fatal bicycle-related trauma in Ontario. Can Med Assoc J. 1995;152(1):45-53.

18. Cowland S. Pedal cyclist collisions and casualties in Greater London. 2008.

19. Kwan I, Mapstone J. Visibility aids for pedestrians and cyclists: a systematic review of randomised controlled trials. Accident Analysis \& Prevention. 2004;36(3):305-12.

20. Hagel BE, Lamy A, Rizkallah JW, Belton KL, Jhangri GS, Cherry N, et al. The prevalence and reliability of visibility aid and other risk factor data for uninjured cyclists and pedestrians in Edmonton, Alberta, Canada. Accident Analysis \& Prevention. 2007;39(2):284-9.

21. Wood JM, Lacherez PF, Marszalek RP, King MJ. Drivers' and cyclists' experiences of sharing the road: Incidents, attitudes and perceptions of visibility. Accident Analysis \& Prevention. 2009;41(4):772-6. 
22. Wood JM, Tyrrell RA, Marszalek R, Lacherez P, Carberry T, Chu BS. Using reflective clothing to enhance the conspicuity of bicyclists at night. Accident Analysis \& Prevention. 2012;45:726-30.

23. Wells S, Mullin B, Norton R, Langley J, Connor J, Lay-Yee R, et al. Motorcycle rider conspicuity and crash related injury: case-control study. British Medical Journal. 2004;328(7444):857-.

24. Thornley SJ, Woodward A, Langley J, Ameratunga S, Rodgers A. Conspicuity and bicycle crashes: preliminary findings of the Taupo bicycle study. Injury Prevention. 2008;14:11-8.

25. Tin Tin S, Woodward A, Ameratunga S. The role of conspicuity in preventing bicycle crashes involving a motor vehicle. European Journal of Public Health. 2015;25(3):517-22.

26. Hagel BE, Romanow NTR, Morgunov N, Embree T, Couperthwaite AB, Voaklander D, et al. The relationship between visibility aid use and motor vehicle related injuries among bicyclists presenting to emergency departments. Accident Analysis \& Prevention. 2014;65:85-96.

27. NOT SHOWN FOR REVIEW PURPOSES

28. Iversen $\mathrm{H}$, Rundmo T. Personality, risky driving and accident involvement among Norwegian drivers. Personality and Individual Differences. 2002;33(8):1251-63.

29. Stephenson MT, Hoyle RH, Palmgreen P, Slater MD. Brief measures of sensation seeking for screening and large-scale surveys. Drug and Alcohol Dependence. 2003;72(3):279-86.

30. Department for Communities and Local Government. The English Indices of Deprivation 2007. 2007.

31. Hosmer D, Lemeshow S. Applied Logistic Regression. Second ed. New York: John Wiley and Sons; 2000.

32. Maldonado G, Greenland S. Simulation study of confounder selection strategies. American Journal of Epidemiology. 1993;138(11):923-36.

33. Watts GR. Bicycle safety devices-effects on vehicle passing distances. Crowthorne: TRRL; 1979.

34. Walker I. Drivers overtaking bicyclists: Objective data on the effects of riding position, helmet use, vehicle type and apparent gender. Accident Analysis \& Prevention. 2007;39:417-425.

35. Aldred R, Woodcock J. Reframing safety: An analysis of perceptions of cycle safety clothing. Transport Policy. 2015;42:103-112. 
Table 1 Characteristics of study participants by case-control status

\begin{tabular}{|c|c|c|c|c|}
\hline & $\begin{array}{c}\text { Control (\%) } \\
n=272\end{array}$ & $\begin{array}{c}\text { Case (\%) } \\
n=76\end{array}$ & $\begin{array}{l}\text { Unadjusted odds } \\
\text { ratio }(95 \% \mathrm{Cl})\end{array}$ & P value $^{a}$ \\
\hline \multicolumn{5}{|l|}{ Age } \\
\hline Mean age in years (SD) & 40.9 (12.7) & $36.2(12.2)$ & $0.96(0.94 \text { to } 0.99)^{\dagger}$ & 0.003 \\
\hline Missing & {$[2]$} & {$[0]$} & & \\
\hline \multicolumn{5}{|l|}{ Gender } \\
\hline Male & $172(63.5)$ & 59 (77.6) & 1.00 & \\
\hline Female & $99(36.5)$ & $17(22.4)$ & $0.52(0.28$ to 0.94$)$ & 0.03 \\
\hline Missing & [1] & {$[0]$} & & \\
\hline \multicolumn{5}{|l|}{ Ethnicity } \\
\hline White British & $228(85.4)$ & $57(75.0)$ & 1.00 & \\
\hline Other & $39(14.6)$ & $19(25.0)$ & 2.22 (1.11 to 4.43$)$ & 0.02 \\
\hline Missing & {$[5]$} & {$[0]$} & & \\
\hline \multicolumn{5}{|c|}{ Index of Multiple Deprivation score } \\
\hline Median (IQR) & $12.7(9.1,23.4)$ & $20.2(12.1,37.0)$ & $1.03(1.01$ to 1.04$) \dagger$ & 0.006 \\
\hline Missing & {$[5]$} & {$[0]$} & & \\
\hline \multicolumn{5}{|l|}{ Driving Licence Holder } \\
\hline No & $43(15.8)$ & $23(30.3)$ & 1.00 & \\
\hline Yes & $229(84.2)$ & $53(69.7)$ & $0.47(0.25$ to 0.89$)$ & 0.02 \\
\hline \multicolumn{5}{|l|}{ Received cycle training at school } \\
\hline No & $119(44.7)$ & $34(46.6)$ & 1.00 & \\
\hline Yes & $147(55.3)$ & $39(53.4)$ & 0.81 (0.47 to 1.39$)$ & 0.45 \\
\hline Missing & {$[6]$} & [3] & & \\
\hline \multicolumn{5}{|l|}{ Received cycle training as an adult } \\
\hline No & $265(97.8)$ & $71(96.0)$ & 1.00 & \\
\hline Yes & $6(2.2)$ & $3(4.0)$ & $1.77(0.39$ to 8.01$)$ & 0.46 \\
\hline Missing & {$[1]$} & [2] & & \\
\hline \multicolumn{5}{|c|}{ Previous cycling crash resulting in injury in the past 3 years } \\
\hline No & $192(71.9)$ & $58(79.4)$ & 1.00 & \\
\hline Yes & $75(28.1)$ & $15(20.6)$ & $0.63(0.34$ to 1.18$)$ & 0.15 \\
\hline Missing & {$[5]$} & [3] & & \\
\hline \multicolumn{5}{|l|}{ Psychometric scores } \\
\hline Normlessness: Median (IQR) & $2.3(2.0$ to 2.8$)$ & $2.0(1.8$ to 2.5$)$ & & \\
\hline Normlessness $<$ median $^{b}$ & $118(44.4)$ & $42(56.8)$ & 1.00 & \\
\hline Normlessness $\geq$ median $^{b}$ & $148(55.6)$ & $32(43.2)$ & 0.57 (0.33 to 0.99$)$ & 0.04 \\
\hline Missing & {$[6]$} & [2] & & \\
\hline Sensation Seeking: Median (IQR) & 2.9 (2.5 to 3.3$)$ & $2.8(2.3$ to 3.4$)$ & & \\
\hline Sensation Seeking $<$ median $^{c}$ & $104(38.5)$ & $32(42.1)$ & 1.00 & \\
\hline Sensation Seeking $\geq$ median $^{c}$ & $166(61.5)$ & $44(57.9)$ & 0.84 (0.49 to 1.44$)$ & 0.53 \\
\hline Missing & [2] & {$[0]$} & & \\
\hline
\end{tabular}

a Wald $p$-values from conditional regression to account for matching

${ }^{b}$ Dichotomised at overall median value of 2.25

${ }^{c}$ Dichotomised at overall median value of 2.75

+ Odds ratio per unit increase. 
Table $\mathbf{2}$ Characteristics of bicycle use and journey characteristics by case-control status

\begin{tabular}{|c|c|c|c|c|}
\hline Characteristic & $\begin{array}{c}\text { Control } n=272 \\
(\%)\end{array}$ & $\begin{array}{c}\text { Case } n=76 \\
(\%)\end{array}$ & $\begin{array}{c}\text { Unadjusted odds } \\
\text { ratio }(95 \% \mathrm{Cl})\end{array}$ & P value* \\
\hline \multicolumn{4}{|c|}{ Regular cyclist (one or more journeys per week since age 16) } & 0.005 \\
\hline$<1$ year & $31(11.5)$ & $16(21.1)$ & 1.00 & \\
\hline $1-3$ years & $48(17.8)$ & $11(14.5)$ & 0.35 (0.13 to 0.94$)$ & \\
\hline $4-10$ years & $29(10.7)$ & $15(19.7)$ & 0.98 (0.38 to 2.50$)$ & \\
\hline$>10$ years & $162(60.0)$ & $34(44.7)$ & $0.34(0.15$ to 0.74$)$ & \\
\hline Missing & {$[2]$} & [0] & & \\
\hline \multicolumn{5}{|c|}{ Distance cycled during the previous week (km) } \\
\hline Median (IQR) & 48.2 (24.2 to 72.5$)$ & $56.4(24.2$ to 96.6$)$ & $1.04(0.99 \text { to } 1.09)^{\mathrm{a}}$ & 0.12 \\
\hline Missing & {$[7]$} & {$[3]$} & & \\
\hline \multicolumn{5}{|c|}{ Number of cycle trips during the previous week } \\
\hline Median (IQR) & $7(4$ to 10$)$ & $7(5$ to 11$)$ & $1.03(0.98 \text { to } 1.08)^{b}$ & 0.26 \\
\hline Missing & [2] & {$[6]$} & & \\
\hline \multicolumn{5}{|l|}{ Route length (km) } \\
\hline Median (IQR) & 4.9 (3.4 to 7.2$)$ & 6.0 (3.8 to 7.8$)$ & 1.02 (0.97 to 1.08$)$ & 0.45 \\
\hline Missing & [9] & [4] & & \\
\hline \multicolumn{5}{|l|}{ Route risk score ${ }^{+}$} \\
\hline Median (IQR) & 268.5 (192.6 to 464.5$)$ & 378.5 (232.4 to 548.3 ) & $1.19(1.06 \text { to } 1.33)^{\mathrm{c}}$ & 0.002 \\
\hline Missing & [35] & [15] & & \\
\hline \multicolumn{5}{|l|}{ Bicycle type } \\
\hline Commuter or folding & $123(46.1)$ & $25(33.3)$ & 1.00 & \\
\hline Mountain or racing & $144(53.9)$ & $50(66.7)$ & 1.87 (1.05 to 3.32$)$ & 0.05 \\
\hline Missing & [5] & [1] & & \\
\hline \multicolumn{5}{|l|}{ Wearing a cycle helmet } \\
\hline No & $94(34.6)$ & $32(42.1)$ & 1.00 & \\
\hline Yes & $178(65.4)$ & $44(57.9)$ & 0.79 (0.46 to 1.38$)$ & 0.41 \\
\hline Lighting conditions & & & & 0.003 \\
\hline Sunshine & $93(34.3)$ & $38(50.0)$ & 1.00 & \\
\hline Overcast & $106(39.1)$ & $17(22.4)$ & 0.22 (0.09 to 0.52 ) & \\
\hline Dawn or dusk & $27(10.0)$ & $5(6.6)$ & 0.17 (0.04 to 0.63$)$ & \\
\hline Dark: street lighting & $43(15.9)$ & $12(15.8)$ & $0.43(0.10$ to 1.82$)$ & \\
\hline Dark: no street lights & $2(0.7)$ & $4(5.3)$ & 3.60 (0.30 to 42.93$)$ & \\
\hline Missing & [1] & [0] & & \\
\hline Weather conditions & & & & 0.07 \\
\hline Good & $212(78.2)$ & $57(76.0)$ & 1.00 & \\
\hline Moderate & $36(13.3)$ & $15(20.0)$ & 1.50 (0.67 to 3.36$)$ & \\
\hline Poor & $23(8.5)$ & $3(4.0)$ & 0.28 (0.08 to 1.05$)$ & \\
\hline Missing & [1] & [1] & & \\
\hline
\end{tabular}


Table 3 Conspicuity aid use by case-control status and unadjusted odds ratios

\begin{tabular}{|c|c|c|c|c|}
\hline & $\begin{array}{c}\text { Control (\%) } \\
n=272\end{array}$ & $\begin{array}{c}\text { Case (\%) } \\
\mathrm{n}=76\end{array}$ & $\begin{array}{l}\text { Unadjusted odds } \\
\text { ratio }(95 \% \mathrm{Cl})\end{array}$ & P value* \\
\hline \multicolumn{5}{|c|}{ Fluorescent and reflective clothing and equipment use } \\
\hline $\begin{array}{l}\text { Any conspicuity aid (any fluorescent or } \\
\text { reflective item on body or on helmet) }\end{array}$ & $178(65.4)$ & $53(69.7)$ & 1.20 (0.66 to 2.17$)$ & 0.55 \\
\hline $\begin{array}{l}\text { Fluorescent and reflective item on body } \\
\text { or helmet }\end{array}$ & $101(37.1)$ & $31(40.8)$ & 1.12 (0.64 to 1.96$)$ & 0.68 \\
\hline Any fluorescent item on body & $119(43.8)$ & $33(43.4)$ & $0.89(0.50$ to 1,58$)$ & 0.69 \\
\hline Any reflective item on body & $160(58.8)$ & $51(67.1)$ & 1.49 (0.84 to 2.64$)$ & 0.18 \\
\hline Fluorescent cycle helmet & $6(2.2)$ & $12(15.8)$ & 6.65 (2.40 to 18.44$)$ & $<0.001$ \\
\hline Reflective cycle helmet & $88(32.4)$ & $26(34.2)$ & $1.12(0.65$ to 1.94$)$ & 0.67 \\
\hline Fluorescent clothing on upper body & $93(34.2)$ & $24(31.6)$ & 0.78 (0.43 to 1.42$)$ & 0.41 \\
\hline Reflective clothing on upper body & $113(41.5)$ & $39(51.3)$ & 1.44 (0.83 to 2.49$)$ & 0.20 \\
\hline Fluorescent clothing on lower body ${ }^{\dagger}$ & $1(0.4)$ & $2(2.6)$ & - & \\
\hline Reflective clothing on lower body & $29(10.7)$ & $17(22.4)$ & 2.76 (1.35 to 5.64$)$ & 0.005 \\
\hline Fluorescent ankle bands or cycle clips & $41(15.1)$ & $6(7.9)$ & 0.47 (0.19 to 1.17$)$ & 0.11 \\
\hline Reflective ankle bands or cycle clips & $25(9.2)$ & $9(11.8)$ & 1.33 (0.56 to 3.15$)$ & 0.52 \\
\hline Lit lights (constant or flashing) & $75(28.1)$ & $27(35.5)$ & 1.59 (0.67 to 3.78$)$ & 0.30 \\
\hline
\end{tabular}

* Wald p-values from conditional regression to account for matching

† Odds ratio omitted owing to the small numbers 
Table 4 Univariate associations between participant and bicycle use characteristics and conspicuity aid use in cases and controls

\begin{tabular}{|c|c|c|c|c|}
\hline \multicolumn{5}{|c|}{ Used a conspicuity aid } \\
\hline Characteristics & $\begin{array}{c}\text { No } \\
\mathrm{N}=117 \text { (row \%) }\end{array}$ & $\begin{array}{c}\text { Yes } \\
\mathrm{N}=231 \text { (row \%) }\end{array}$ & $\begin{array}{l}\text { Unadjusted odds } \\
\text { ratio }(95 \% \mathrm{Cl})\end{array}$ & $\begin{array}{c}P \\
\text { value }\end{array}$ \\
\hline \multicolumn{5}{|l|}{ Age } \\
\hline Mean age in years (SD) & $38.8(15.0)$ & $40.4(11.3)$ & 1.01 (0.99 to 1.03$)$ & 0.28 \\
\hline Missing & [1] & {$[1]$} & & \\
\hline \multicolumn{5}{|l|}{ Gender } \\
\hline Male & $83(35.9)$ & $148(64.1)$ & 1.00 & \\
\hline Female & $34(29.3)$ & $82(70.7)$ & 1.35 (0.84 to 2.19$)$ & 0.22 \\
\hline Missing & [0] & [1] & & \\
\hline \multicolumn{5}{|l|}{ Deprivation score } \\
\hline Median (IQR) & $13.7(9.9,32.1)$ & $14.6(9.1,26.1)$ & 0.99 (0.98 to 1.01$)$ & 0.31 \\
\hline Missing & {$[2]$} & [3] & & \\
\hline \multicolumn{5}{|l|}{ Possession of a driving licence } \\
\hline No Driving Licence & 27 (40.9) & $39(59.1)$ & 1.00 & \\
\hline Driving Licence & 90 (31.9) & $192(68.1)$ & $1.48(0.85$ to 2.56$)$ & 0.17 \\
\hline \multicolumn{5}{|c|}{ Bicycle proficiency training during childhood } \\
\hline No training & $52(34.0)$ & $101(66.0)$ & 1.00 & \\
\hline Had training & $63(33.9)$ & $123(66.1)$ & 1.01 (0.64 to 1.58$)$ & 0.98 \\
\hline Missing & [2] & [7] & & \\
\hline \multicolumn{5}{|c|}{ Bicycle crash causing injury in the previous three years } \\
\hline No previous crash & $93(37.2)$ & $157(62.8)$ & 1.00 & \\
\hline Previous crash & $23(25.6)$ & $67(74.4)$ & 1.73 (1.01 to 2.96$)$ & 0.05 \\
\hline Missing & [1] & [7] & & \\
\hline \multicolumn{5}{|c|}{ Wearing a helmet during the crash or study journey } \\
\hline Not wearing helmet & $79(62.7)$ & $47(37.3)$ & 1.00 & \\
\hline Wearing helmet & $38(17.1)$ & $184(82.9)$ & 8.14 (4.93 to 13.45$)$ & $<0.001$ \\
\hline \multicolumn{3}{|c|}{ Cycling experience (years regular cycling as an adult) } & & 0.57 \\
\hline$<1$ year & $15(31.9)$ & $32(68.1)$ & 1.00 & \\
\hline $1-3$ years & $20(33.9)$ & $39(66.1)$ & 0.91 (0.40 to 2.07$)$ & \\
\hline $4-10$ years & $19(43.2)$ & $25(56.8)$ & 0.62 (0.26 to 1.45$)$ & \\
\hline$>10$ years & $63(32.1)$ & $133(67.9)$ & $0.99(0.50$ to 1.96$)$ & \\
\hline Missing & {$[0]$} & [2] & & \\
\hline \multicolumn{5}{|l|}{ Bicycle type } \\
\hline Commuter or folding bicycle & $42(29.2)$ & $102(70.8)$ & 1.00 & \\
\hline Racing or mountain bicycle & $70(37.0$ & $119(63.0)$ & $0.70(0.44$ to 1.11$)$ & 0.13 \\
\hline Missing & [5] & [10] & & \\
\hline \multicolumn{5}{|l|}{ Normlessness } \\
\hline median (IQR) & $2.25(1.75,2.75)$ & $2.25(1.75,2.50)$ & & \\
\hline$\leq$ median & $47(29.4)$ & $113(70.6)$ & 1.00 & \\
\hline$>$ median & 66 (36.7) & $114(63.3)$ & $0.72(0.46$ to 1.13$)$ & 0.16 \\
\hline Missing & {$[4]$} & [4] & & \\
\hline \multicolumn{5}{|l|}{ Sensation Seeking } \\
\hline median $(I Q R) \dagger$ & $3.0(2.5,3.5)$ & $2.75(2.25,3.25)$ & & \\
\hline$\leq$ median & $38(27.9)$ & $98(72.1)$ & 1.00 & \\
\hline > median & $79(37.6)$ & $131(62.4)$ & 0.64 (0.40 to 1.03$)$ & 0.06 \\
\hline Missing & {$[0]$} & [2] & & \\
\hline \multicolumn{5}{|c|}{ Light levels during crash or study journey } \\
\hline Sunshine & 49 (37.4) & $82(62.6)$ & 1.00 & $<0.001$ \\
\hline
\end{tabular}




\begin{tabular}{|c|c|c|c|c|}
\hline Overcast & $53(43.1)$ & 70 (56.9) & 0.79 (0.48 to 1.30$)$ & \\
\hline Dawn or dusk & $6(18.8)$ & $26(81.3)$ & 2.59 (1.00 to 6.73$)$ & \\
\hline Darkness $^{a}$ & $9(14.8)$ & $52(85.3)$ & 3.45 (1.57 to 7.62$)$ & \\
\hline Missing & [0] & [1] & & \\
\hline \multicolumn{5}{|l|}{ Route length (km) } \\
\hline median (IQR) & $4.0(2.4,6.1)$ & $6.0(4.3,7.9)$ & & \\
\hline$\leq$ median $\dagger$ & $79(46.2)$ & $92(53.8)$ & 1.00 & \\
\hline$>$ median & $33(20.1)$ & 131 (79.9) & 3.41 (2.10 to 5.54$)$ & $<0.001$ \\
\hline Missing & {$[5]$} & [8] & & \\
\hline \multicolumn{5}{|c|}{ Distance cycled in the previous 7 days $(\mathbf{k m})$} \\
\hline Median (IQR) & $38.6(16.1,64.4)$ & $48.3(28.9,80.5)$ & & \\
\hline$\leq$ median & $75(39.1)$ & $117(60.9)$ & 1.00 & \\
\hline$>$ mediant & $36(24.7)$ & $110(75.3)$ & 1.96 (1.22 to 3.15$)$ & \\
\hline Missing & {$[6]$} & {$[4]$} & & \\
\hline \multicolumn{5}{|l|}{ Route risk ${ }^{b}$} \\
\hline median (IQR) & $272.3(203.7,413.4)$ & $308.1(198.0,504.3)$ & & \\
\hline$\leq$ median ${ }^{\dagger}$ & $53(35.6)$ & $96(64.4)$ & 1.00 & \\
\hline$>$ median & $43(28.9)$ & $106(71.1)$ & 1.36 (0.84 to 2.22 ) & 0.22 \\
\hline Missing & [21] & [29] & & \\
\hline
\end{tabular}

${ }^{a}$ Street-lighting and darkness with no street-lighting combined due to small numbers in each cell

${ }^{b}$ Estimated bicycle crashes per 100 million cyclists per kilometre along each participant's route

+ dichotomised at the median as non-linear association with conspicuity aid use 
Table 5 Adjusted odds ratios $(95 \% \mathrm{Cl})$ in final multivariable model for collision or evasion crash by conspicuity aid use

\begin{tabular}{lcc}
\hline Variable & Odds Ratio $(95 \% \mathrm{Cl})$ & P value \\
\hline Any conspicuity aid & $2.43(1.06$ to 5.59$)$ & 0.04 \\
Age (per year) & $0.97(0.94$ to 1.01$)$ & 0.12 \\
Sex (female vs male) & $0.37(0.15$ to 0.89$)$ & 0.03 \\
Index of multiple deprivation & $1.04(1.02$ to 1.07$)$ & 0.002 \\
Previous cycle crash & $0.36(0.15$ to 0.88$)$ & 0.03 \\
Route risk score* & $1.16(1.02$ to 1.31$)$ & 0.03 \\
\hline
\end{tabular}

* Per additional 100 cycle crashes per 100 million cyclists per kilometre of route 
Table 6 Odds ratios for the risk of a collision or evasion crash associated with any conspicuity aids with adjustment for each individual potential confounder

\begin{tabular}{|c|c|c|c|}
\hline Confounder adjustment & $\begin{array}{l}\text { Odds ratio ( } 95 \% \mathrm{Cl} \text { ) for } \\
\text { conspicuity aid use }\end{array}$ & $P$ value & $\mathbf{n}$ \\
\hline Unadjusted & 1.20 (0.66 to 2.17$)$ & 0.55 & 348 \\
\hline \multicolumn{4}{|l|}{ Adjusted by: } \\
\hline Age & 1.32 (0.71 to 2.42 ) & 0.38 & 346 \\
\hline Gender & 1.24 (0.68 to 2.26$)$ & 0.49 & 347 \\
\hline Index of multiple deprivation & 1.35 (0.74 to 2.50$)$ & 0.33 & 342 \\
\hline Driving Licence holder & 1.27 (0.69 to 2.33 ) & 0.45 & 348 \\
\hline Childhood cycle training & 1.19 (0.65 to 2.20$)$ & 0.57 & 333 \\
\hline Previous cycle crash & 1.11 (0.60 to 2.04 ) & 0.74 & 329 \\
\hline Normlessness Score & 1.17 (0.64 to 2.14$)$ & 0.61 & 346 \\
\hline Sensation Seeking Score & 1.18 (0.65 to 2.14$)$ & 0.60 & 346 \\
\hline Cycling Experience & 1.43 (0.78 to 2.64$)$ & 0.25 & 346 \\
\hline Route Length & 1.07 (0.57 to 2.00$)$ & 0.83 & 323 \\
\hline Route risk $^{*}$ & 1.64 (0.82 to 3.28$)$ & 0.16 & 258 \\
\hline Bicycle type & 1.30 (0.71 to 2.38$)$ & 0.39 & 325 \\
\hline Wearing a cycle helmet & $1.40(0.73$ to 2.71$)$ & 0.31 & 348 \\
\hline Light Level & 1.26 (0.67 to 2.35$)$ & 0.48 & 347 \\
\hline Weather conditions & $1.20(0.65$ to 2.21$)$ & 0.56 & 340 \\
\hline
\end{tabular}

${ }^{*}$ Per additional 100 cycle crashes per 100 million cyclists per kilometre of route 
Figure 1 Recruitment by case-control status

Adult cyclists screened after attending study site ED after injury cycle crash $n=571$

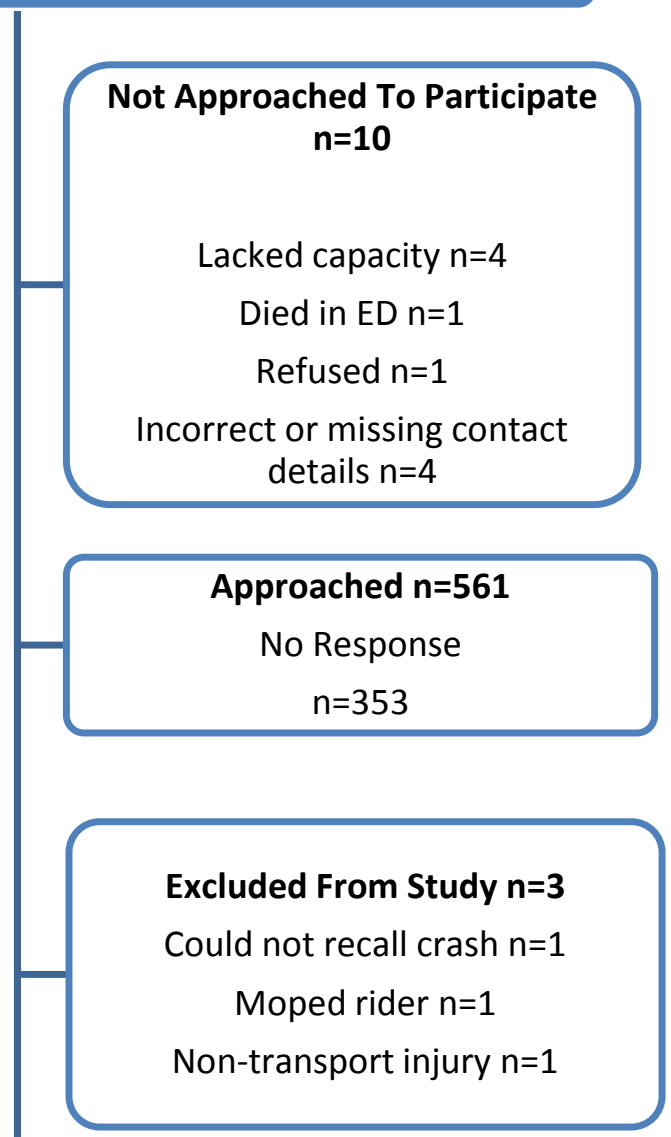

\section{Questionnaires received $\mathrm{n}=\mathbf{2 0 5}$}

Excluded From Matched Analysis $n=129$

Crash out of area $n=7$

Crash out of hours $n=2$

Unusable data $\mathrm{n}=4$

No available controls $n=7$

Out of time for controls $n=4$

Ineligible journey purpose $n=36$

Non-Collision / Evasion Crash n=69

\section{Cases}

$n=76(13 \%)$
Adult cyclists approached at local

companies, organisations or public places $n=505$

Not given Study Pack $n=42$

Refused $n=27$

Refused second approach $n=15$

Pack given $n=463$

No reponse $n=170$

Questionnaires received $\mathbf{n}=\mathbf{2 9 3}$

Excluded from matched analysis

$$
\mathrm{n}=\mathbf{2 1}
$$

Non-matched day of journey $n=5$ Non-matched journey purpose $n=9$ Non-matched time of journey $n=7$

\section{Controls}

$n=272 \quad(54 \%)$ 